\title{
Periferização, qualidade ambiental urbana e percepção dos moradores em cidades médias: estudo de caso no município de Itajubá/MG
}

\author{
Periphery, urban environmental quality and perception of residents in medium-sized cities: a case \\ study in the municipality of Itajubá/MG \\ Periferia, calidad ambiental urbana y percepción de habitantes en ciudades medianas: un estudio \\ de caso en el municipio de Itajubá/MG
}

Recebido: 22/12/2020 | Revisado: 24/12/2020 | Aceito: 28/12/2020 | Publicado: 02/01/2021

\author{
Guilherme Prado Alves \\ ORCID: https://orcid.org/0000-0003-3978-0270 \\ Universidade Federal de Itajubá, Brasil \\ E-mail: guilhermepradoalves@unifei.edu.br \\ Luciana Botezelli \\ ORCID: https://orcid.org/0000-0002-5916-0442 \\ Universidade Federal de Alfenas, Brasil \\ E-mail: luciana.botezelli@gmail.com \\ Maria Cláudia Costa de Oliveira Botan \\ ORCID: https://orcid.org/0000-0002-6299-9732 \\ Universidade Virtual do Estado de São Paulo, Brasil \\ E-mail: maclau_oliveira@hotmail.com \\ Daniele Ornaghi Sant'Anna \\ ORCID: https://orcid.org/0000-0003-0271-1693 \\ Universidade Federal de Itajubá, Brasil \\ E-mail: ornaghi@unifei.edu.br
}

\begin{abstract}
Resumo
Em grandes metrópoles percebe-se a existência de irregularidades socioambientais decorrentes da urbanização, especialmente em regiões periféricas dos centros urbanos. Tal realidade se reproduz em cidades médias e pequenas. Este trabalho consiste em um estudo de caso para compreender as questões associadas a qualidade ambiental urbana periférica de uma cidade média - no caso o município de Itajubá - por intermédio de uma comparação entre dois bairros com características distintas, porém semelhantes sob o conceito de "periferia". A avaliação da qualidade ambiental urbana foi realizada por métodos objetivos (estudo técnico-científico das formas de uso e ocupação do solo, dos espaços livres e da cobertura vegetal) e subjetivos (aplicação de questionários levando em consideração a percepção socioambiental dos moradores e usuários dos bairros). Os resultados obtidos permitiram a construção de um panorama da qualidade ambiental urbana em cada um dos bairros, que foram analisados apontando suas principais diferenças. Foi notada grande distinção a respeito das condições socioeconômicas entre os moradores dos dois bairros e diferentes perspectivas a respeito do meio ambiente onde estão inseridos. O entendimento das diferentes percepções ambientais de pessoas que vivem em uma mesma cidade é fundamental para a criação de programas de conservação e preservação do meio ambiente.
\end{abstract}

Palavras-chave: Periferização; Qualidade ambiental urbana; Análise comparativa.

\begin{abstract}
In large metropolises, there are socio-environmental irregularities resulting from urbanization, especially in peripheral regions of urban centers. This reality is reproduced in medium and small cities. This work consists of a case study to understand the issues associated with the peripheral urban environmental quality of a medium-sized city - in this case, the municipality of Itajubá - through a comparison between two neighborhoods with distinct characteristics, but similar under the concept of "periphery". The evaluation of urban environmental quality was carried out by objective (technical-scientific study of the forms of use and occupation of the soil, free spaces and vegetation cover) and subjective methods (application of questionnaires taking into account the socio-environmental perception of residents and users of neighborhoods). The results obtained allowed the construction of a panorama of urban environmental quality in each of the neighborhoods, which were analyzed pointing out their main differences. A great distinction was noted regarding the socioeconomic conditions among the residents of the two neighborhoods and different perspectives regarding the environment in which they operate. Understanding the different environmental perceptions
\end{abstract}


of people living in the same city is essential for the creation of environmental conservation and preservation programs.

Keywords: Periphery; Urban environmental quality; Comparative analysis.

\section{Resumen}

En las grandes metrópolis, existen irregularidades socioambientales derivadas de la urbanización, especialmente en las regiones periféricas de los centros urbanos. Esta realidad se reproduce en ciudades medianas y pequeñas. Este trabajo consiste en un estudio de caso para comprender los problemas asociados a la calidad ambiental urbana periférica de una ciudad de tamaño mediano - en este caso, el municipio de Itajubá - mediante la comparación entre dos barrios con características distintas pero similares bajo el concepto de "periferia". La evaluación de la calidad ambiental urbana se realizó por métodos objetivos (estudio técnico-científico de las formas de uso y ocupación del suelo, espacios libres y cobertura vegetal) y subjetivos (aplicación de cuestionarios teniendo en cuenta la percepción socioambiental de los residentes y usuarios de barrios). Los resultados obtenidos permitieron construir un panorama de calidad ambiental urbana en cada uno de los barrios, los cuales fueron analizados señalando sus principales diferencias. Se notó una gran distinción en cuanto a las condiciones socioeconómicas entre los habitantes de los dos barrios y las diferentes perspectivas sobre el entorno en el que operan. Comprender las diferentes percepciones ambientales de las personas que viven en una misma ciudad es fundamental para la creación de programas de conservación y preservación ambiental.

Palabras clave: Periferia; Calidad Ambiental Urbana; Análisis Comparativo.

\section{Introduçãa}

O processo de urbanização trouxe consigo inúmeras interferências na qualidade de vida da população, principalmente no que diz respeito ao planejamento ineficaz associado aos diferentes usos e ocupações do solo e modificações climáticas e ambientais, que transformam o espaço natural em um ecossistema próprio de centros urbanos (Camargo \& Amorim, 2005). As perturbações na qualidade de vida da população são avaliadas e percebidas por meio dos sinais de degradação da qualidade ambiental urbana, uma vez que são fatores correlatos. Tais problemas são perceptíveis por doenças respiratórias, estresse, desconforto térmico, incidência de pragas, entre outros aliados à poluição, ausência de políticas públicas adequadas e gestão urbana ineficiente, que contribuem diretamente para a construção de um espaço urbano pouco sustentável (D. Santos, 2008; Martins, Salles, Macedo, Nunes, \& Ribeiro, 2020).

Lima (2014) afirma que, tanto em grandes metrópoles quanto em pequenas cidades, é comum encontrar inúmeros bairros com problemas socioambientais evidentes, especialmente quando localizados em periferias e assentamentos irregulares. A periferia do município de Itajubá, MG, apesar de apresentar características distintas nos bairros que a compõe, assimila inúmeras questões ambientais que servem como base para uma análise comparativa da qualidade ambiental urbana entre seus elementos.

O Bairro das Nações, localizado às margens da rodovia BR-439, apresenta uma forte heterogeneidade na sua composição. Algumas ruas não são pavimentadas e totalmente impróprias para o trânsito de veículos e de pedestres, além de apresentar loteamentos com solo exposto, susceptíveis a erosão no período chuvoso. O contraste socioeconômico torna-se evidente ao observar a construção de um loteamento de alto padrão nas imediações de um conjunto habitacional de cunho social. Ao mesmo passo que o bairro abriga o Laboratório Nacional de Astrofísica (LNA), ele não possui instalações comerciais e sociais básicas essenciais à população ali residente, como escolas, postos de saúde, mercearias e restaurantes.

O Bairro Pinheirinho, por sua vez, localizado nas imediações da Universidade Federal de Itajubá (Unifei), contém apenas residências de alto padrão, em loteamentos ou condomínios fechados. Apesar de não apresentar comércio ou outras instalações para usufruto da população residente, o bairro encontra-se muito próximo da prefeitura e do teatro municipal, do parque da cidade e de uma escola, além da mencionada universidade. O bairro apresenta uma arborização visualmente satisfatória, capaz de fornecer bom sombreamento, uma praça em um ponto estratégico e áreas permeáveis por quase toda sua extensão.

Apesar de se tratarem de pontos distantes de uma centralidade, caracterizados como "periferia" segundo Serpa (2007), 
os bairros mostram características bastante distintas entre si, permitindo uma análise comparativa de modo a compreender as transformações e as formas de organização da sociedade que induziram a essas notáveis diferenças e seus impactos na qualidade ambiental urbana e na qualidade de vida da população.

Com base na notória expansão urbana observada no município de Itajubá - MG, este trabalho buscou compreender as diferenças existentes entre dois bairros com características socioambientais distintas, porém semelhantes sob a definição de periferia. Nesse sentido, foram definidos como objetos de estudo os bairros Pinheirinho e Nações.

O objetivo geral deste trabalho foi realizar um estudo comparativo entre dois bairros afastados da centralidade do município de Itajubá (MG), Pinheiro e Nações, sob o ponto de vista da qualidade ambiental urbana, avaliando os processos de periferização em regiões da cidade que assumiram características distintas ao longo do processo de expansão urbana.

Como objetivos específicos, buscou-se: i) realizar um levantamento das formas de ocupação e de uso do solo nos bairros ao longo dos anos; ii) elaborar um estudo a respeito da qualidade ambiental urbana associada a presença de áreas verdes e vegetação nas localidades propostas com base na percepção socioambiental dos moradores e usuários dos bairros; iii) avaliar, de modo comparativo, a qualidade ambiental urbana em cada bairro estudado.

\section{Fundamentação Teórica}

O meio urbano, como conjunto complexo e interativo, forma-se por meio de acontecimentos históricos de cunho econômico, político, social e cultural, até alcançar suas configurações atuais (K. de O. Silva, 2006).

De acordo com A. P. Santos, Polidori, Peres e Saraiva (2017), o crescimento urbano contemporâneo recebe grande influência dos contextos sociais e econômicos, dando origem a processos de urbanização com características inovadoras. Nesse sentido, novos formatos de organização das cidades têm suscitado importantes transformações nas interações sociais, tanto na sua produção quanto em suas atividades.

No Brasil, o processo de urbanização se intensificou a partir das décadas de 1930 e 1940, quando a formação das cidades se associou às transformações pelas quais passavam a sociedade e a economia brasileira (Brito, Horta, \& Amaral, 2001). Segundo Martine, Camarano, Neupert e Beltrão (2016), esse período foi caracterizado pela reestruturação e reformulação da rede urbana brasileira, especialmente no que tange às mudanças provocadas pela quebra da hegemonia agrária e pelo impacto dinamizador do crescimento da economia industrial associado às migrações rural-urbanas. O país abandonou um arranjo litorâneo, esparso e descentralizado e passou a incorporar localidades urbanas de porte considerável em pontos estratégicos de todo o território.

Os fluxos migratórios do campo para as cidades foram responsáveis pela criação de um novo desenho do espaço urbano, segmentando a maioria dos municípios em duas partes evidentemente distintas: a primeira, localizada nas regiões centrais, com instalações legalizadas e que concentram a população de classes média e alta; e a segunda, destinada às residências das populações de classes baixas, marcadas pela criação de loteamentos ilegais e irregulares, que se expandiram como conjunto de habitações precariamente construídos e desprovidos e de infraestrutura, desencadeando o processo de periferização e favelização das cidades (Sopran \& Debarba, 2008)

Em decorrência dos problemas que surgem dessa polarização socioespacial, o termo periferia ganhou forças nos debates e pesquisas acadêmicas voltados para os mais diversos setores da sociedade (Chaveiro, 2007). Segundo Serpa (2007), a palavra "periferia", de maneira geral, diz respeito às áreas urbanas distantes de uma determinada centralidade. Entretanto, atualmente, a periferia urbana tomou uma nova conotação sociológica, na qual ela se diferencia do restante da cidade pela precariedade de sua configuração espacial (Paviani, 1994).

Nesse sentido, Lobato (2004) afirma a existência de duas periferias no contexto urbano: aquela com urbanização de status e aquela com urbanização popular. A periferia nobre se compõe pela população de classes sociais mais elevadas, 
aproveitando-se das amenidades físicas, como luminosidade e espaços naturais, e da infraestrutura sociocultural. Em vista da conotação sociológica pejorativa assumida pelo termo periferia, essas regiões fisicamente afastadas do centro não são percebidas como periferia, uma vez que não são consideradas socialmente periféricas.

Por outro lado, Bonduki, Andrade, Bonduki e Rossetto (1993) define as zonas de urbanização popular como espaços ocupados pela população de baixa renda, caracterizadas, em sua maioria, pela presença de conjuntos habitacionais assinalados pelo desprezo da qualidade arquitetônica e urbanística e pela preferência por soluções homogêneas e uniformizadas.

A dinâmica de acesso ao uso do solo contribuiu com a formação histórica do valor da terra. Grandes indústrias e prestadoras de serviços que necessitam de espaços amplos para suas instalações, bem como as classes menos favorecidas da população, procuram locais distantes das centralidades urbanas para construírem suas edificações, onde geralmente observa-se preços de lotes mais acessíveis. Entretanto, atualmente, devido à alta densidade de áreas centrais e sua ocupação por complexos de lazer, casas noturnas e hotéis, a classe dominante central começa a migrar para regiões afastadas em busca de qualidade de vida e tranquilidade, construindo bairros de luxo, jardins, condomínios fechados. Apesar da proximidade entre os terrenos, é possível notar claramente as diferenças sociais e econômicas entre os grupos que passaram a ocupar as periferias, principalmente por meio das edificações e dos estilos de vida vivenciados no espaço construído (Zorzanello \& Müller, 2013).

As mudanças no desenho urbano orientadas pela pós-modernidade têm transformado áreas que já apresentaram boa infraestrutura, e até chegaram a ser centralidades no passado, em regiões periféricas, principalmente por não acompanharem as necessidades urbanas contemporâneas. O oposto também é válido, tomando como exemplo áreas geometricamente distantes do centro que deixaram de pertencer a periferia por suas características arquitetônicas de grande capital e ações efetivas de valorização por parte do Estado e consequentemente pelo ramo imobiliário, assumindo características de novas centralidades (Ritter \& Firkowski, 2009).

A periferia, assim, mostra-se cada vez mais segregada. Com relação aos espaços públicos, em geral, nota-se uma valorização e concentração de usuários nas centralidades, em detrimento de áreas abandonadas nas zonas periféricas. É visível um isolamento não só exterior das periferias, mas também interior aos bairros, resultante da falta de planejamento e da existência de inúmeras construções irregulares que impedem a circulação e uso de espaços de importância local (Serpa, 2007).

De acordo com Zorzanello e Müller (2013), as cidades, independentemente de sua extensão territorial são espaços de diversas interações morais, culturais e religiosas, refletindo realidades de grupos sociais com características de ocupação distintas, que vivem em uma mesma área geográfica. Lobato (2004) afirma que o espaço urbano é retrato da estrutura social hierarquizada em classes: as cidades se compõem de forma extremamente desigual e os modos de ocupação do solo assumem caráter de condicionante social, uma vez que a terra se relaciona com às funções, à movimentação e às atividades vinculadas aos processos da sociedade.

Derivando da dinâmica de acumulação do capital e das relações de produção, Maia (2010) apresenta o processo de expansão das cidades no Brasil pelas seguintes formas de ocupação: grandes loteamentos oficiais, destinados à camada da população possuidora dos mais altos rendimentos; loteamentos irregulares, cujos projetos não foram aprovados pelo Poder Público ou que desrespeitam as normas definidas pelo parcelamento urbano; loteamentos clandestinos, executados sem qualquer tipo de consulta aos Órgãos Públicos, desrespeitando as normas urbanísticas; áreas precárias de habitação de forma irregular, também conhecidas como favelas.

Pereira e L. de O. L. Santos (2012) afirmam que tais processos de ocupação do solo, associados às atividades econômicas, como indústria e agricultura, resultam em alterações na qualidade da água, do ar, do solo e de outros recursos naturais, podendo causar interferências diretas sobre a qualidade de vida de uma população. A partir de 1760, com o advento industrial na Inglaterra, tornaram-se visíveis as precárias condições sanitárias e habitacionais da emergente classe operária inglesa. No Brasil, o processo foi bastante semelhante com a expansão dos cortiços e das favelas nos primórdios da 
industrialização. Nesse sentido, as periferias urbanas passaram a assumir caráter fortemente associado a violência urbana, à degradação do meio ambiente e ao desrespeito à ordem urbana (D. Santos, 2008).

O fenômeno de massificação urbana trouxe consigo diversos problemas habitacionais e ambientais, em decorrência de um intenso êxodo rural provocado pela criação de um centro de produção nas cidades. Essa crescente concentração urbana contribuiu com a ampliação das carências sociais e com a deterioração do meio ambiente e da qualidade de vida, uma vez que grande soma das famílias provenientes do campo, com baixas condições financeiras e motivadas pelas oportunidades oferecidas pela vida urbana, passou a ocupar áreas de invasão em morros e periferias, intrinsecamente caracterizados pela presença de estoques de terras livres, ausência de infraestrutura instalada, precariedade de serviços públicos, longa distância dos centros urbanos, baixa qualidade de loteamentos e clandestinidade generalizada (L. S. e Silva \& Travassos, 2008). Tal processo contribuiu com a formação de um centro de consumo nas cidades, onde uma parcela da população passou a ter acesso a um nível aquisitivo elevado, outra alcançou um padrão de consumo moderado enquanto a grande maioria sequer satisfaz suas necessidades físicas materiais (Tavares Filho, 2017).

Em geral, a periferia, sobretudo a população pobre residente nesses espaços, é considerada um empecilho a preservação ambiental. Entretanto, segundo Tavares Filho (2017), as populações pobres, apesar de causarem degradação por suas formas de ocupação irregular e de risco, é por si só “mais ecológica”, uma vez que possui padrão de consumo inferior ao das demais classes e, muitas vezes, vive de resíduos que são reciclados ou reutilizados. Alier (1998) ressalta que não é a pobreza responsável pela má qualidade ambiental urbana, mas sim a desigualdade provocada por forças econômicas, sociais, políticas e institucionais, que beneficiam uns em detrimento de outros.

Via de regra, a periferização e a ocupação intra-urbana por moradias precárias e irregulares se processam em áreas desprezadas pelo mercado imobiliário formal e/ou em áreas de restrição de uso, como áreas de proteção ambiental, terrenos sujeitos a enchentes, encostas de morros e margens de córregos, frequentemente associadas a algum tipo de risco físico ou natural. Esses espaços, que por tais motivos jamais deveriam ser ocupados, dão suporte a expansão urbana precária e predatória, contribuindo com criação de zonas de vulnerabilidade ambiental nas cidades (Maricato, 1999).

Como apontam Caccia, Evers, Fernandes e Betti (2017), a expansão das zonas urbanas implicam necessariamente em impactos ambientais sobre o espaço natural. Esses impactos podem ser intensificados quando a ocupação ocorre de forma irregular, ignorando as exigências técnicas necessárias ao parcelamento do solo e desrespeitando a capacidade limite do meio físico. Nesse contexto, os impactos tomam proporções mais acentuadas e resultam em consequências sobre toda a malha urbana.

A percepção ambiental do cidadão, aliada ao envolvimento dos órgãos municipais com relação a problemática ambiental e ao uso racional dos recursos naturais, pode resultar na formação de um espaço urbano sustentável. Assim, faz-se necessário planejamento e utilização de tecnologias adequadas com o intuito de contribuir para o bem-estar de cada um e da sociedade (Evaristo, Cordeiro, Alvarenga, Oporto, Quintão, Calazans, \& Cordeiro, 2017; Melazo, 2019).

Dessa forma, a qualidade de vida, associada a qualidade ambiental urbana e a moradia tem tomado grande espaço nos meios acadêmicos, políticos, sociais e culturais, principalmente por se relacionar a questões importantes a respeito de desenvolvimento sustentável e de sustentabilidade urbana (Kran \& Ferreira, 2006).

\section{Materiais e Métodos}

Para este trabalho foi adotado como delineamento de pesquisa o estudo de caso aliado a uma abordagem qualitativa.

O estudo de caso se mostra apropriado ao trabalho por permitir a tomada de conhecimento sobre o fenômeno da periferização em cidades de médio porte, assumindo como objeto de estudo o município de Itajubá. Além disso, a proposta de descrição e análise detalhadas são fundamentais para construção de um banco de dados e informações que podem contribuir à 
área de planejamento urbano e ambiental (Pereira, Shitsuka, Parreira, \& Shitsuka, 2018; Yin, 2005).

Como a pesquisa considera relevante os significados e valores atribuídos pelas pessoas ao fenômeno, foi adotado como metodologia de análise a abordagem qualitativa. Tal método permite interpretações sob as perspectivas e conhecimentos dos próprios pesquisadores (Pereira et al., 2018). Vale ressaltar que, ainda que tenham sido utilizados dados numéricos, a proposta desta pesquisa se assenta sobre a interpretação do fenômeno e não sobre a sua quantificação.

Em síntese, com base nos aspectos culturais, socioeconômicos e intelectuais distintos entre indivíduos e grupos de indivíduos, a metodologia desenvolvida busca estudar a realidade de forma objetiva e subjetiva. Logo, adota-se, para o presente trabalho, um método semelhante ao desenvolvido por Borja (1997), avaliando aspectos subjetivos e objetivos relacionados a qualidade ambiental urbana nos bairros estudados, assumindo os parâmetros definidos por Nucci (2011) em "Metodologia para determinação da qualidade ambiental urbana". Borja (1997) propõe uma avaliação da qualidade ambiental urbana (QAU) por meio de oito categorias de análise: moradia, saneamento, infraestrutura urbana, serviços urbanos, infraestrutura social e cultural, conforto do ambiente, paisagem urbana e cidadania. O modelo inclui, ainda, variáveis, indicadores e métodos subjetivos aliados a perspectivas técnico-científica e cultural. Com base nesses preceitos, a proposta metodológica desenvolvida neste trabalho é indicada pela Figura 1, que representa o fluxograma de avaliação da qualidade ambiental urbana:

Figura 1: Proposta metodológica para a avaliação da Qualidade Ambiental Urbana nos bairros de Itajubá.

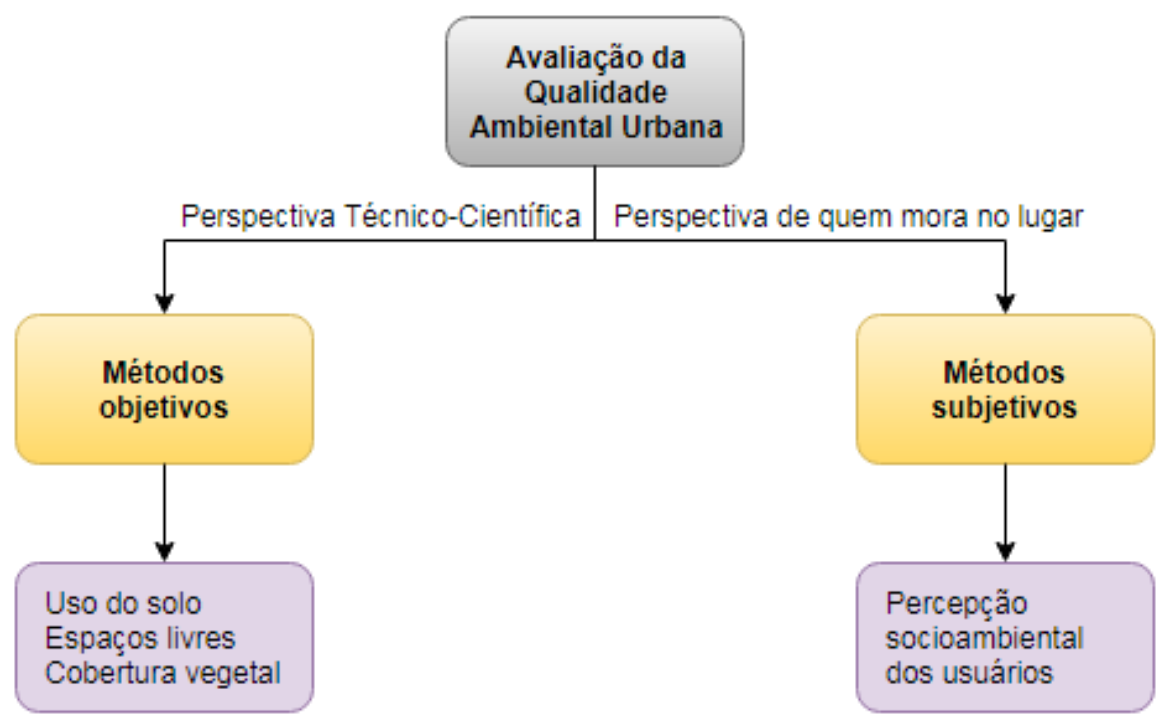

Fonte: Adaptado de Borja (1997).

A Figura 1 ilustra como a qualidade ambiental urbana foi avaliada: por meio de uma perspectiva técnico científica, que se utilizou de métodos objetivos para a coleta e análise de dados sobre uso do solo, espaços livres e cobertura vegetal; e uma perspectiva de quem mora no lugar, utilizando métodos subjetivos para levantar informações sobre a percepção socioambiental dos usuários.

Para o levantamento dos dados subjetivos, foram aplicados questionários efetivos entre os moradores e usuários dos bairros estudados para posterior análise. Segundo D. Santos (2008), a interpretação de dados baseados em relatos pessoais permite a observação de como o homem age no meio em que habita e, em decorrência, como a sociedade age sobre a natureza. O questionário foi elaborado a partir de um inventário de dados construído no segundo semestre de 2018 e aplicado nas áreas indicadas pela Figura 2. 
Figura 2: Área de aplicação de questionários nos bairros Pinheirinho (a) e Nações (b).
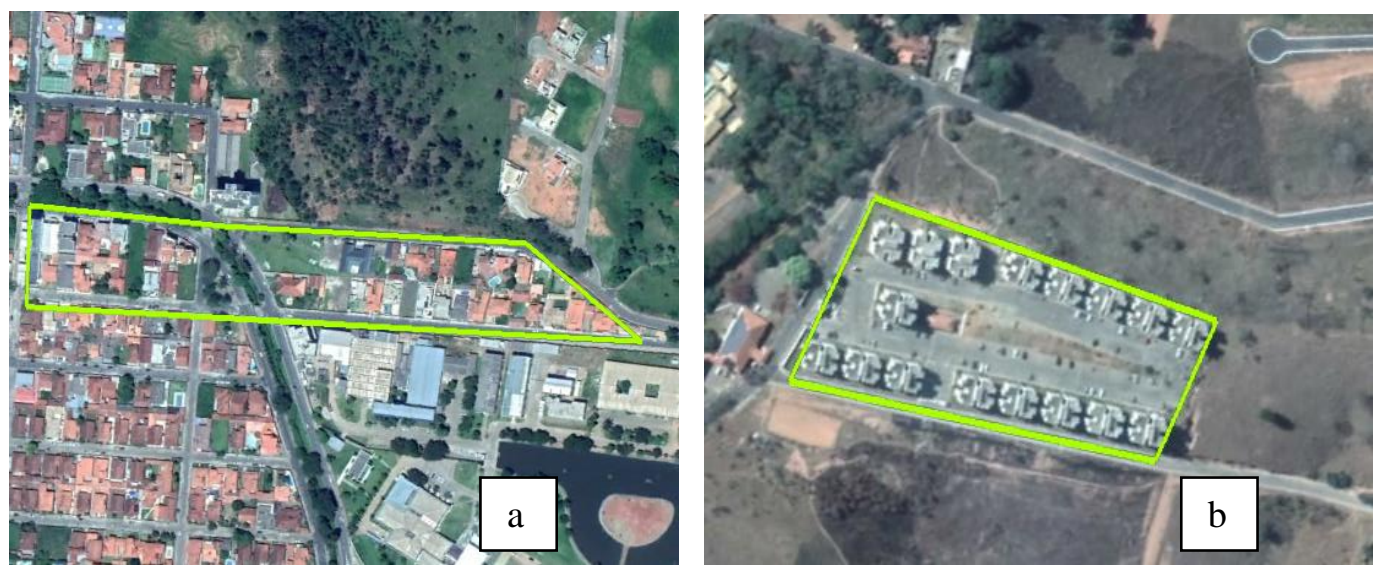

Fonte: Google Earth (2018).

A área de aplicação dos questionários foi delimitada considerando a acessibilidade dos pesquisadores aos locais e o perímetro dos bairros apresentados pelo portal OpenStreetMaps.

Foram aplicados 111 questionários, sendo 67 no bairro Pinheirinho e 44 no bairro Nações. Os questionários constituem-se em vinte perguntas que buscam descrever a situação socioeconômica do entrevistado, bem como sua percepção ambiental sobre o local em que está inserido.

Os dados objetivos, por sua vez, foram obtidos por meio da identificação de espaços verdes, massas arbóreas e áreas permeáveis dos bairros e seu posterior mapeamento em Sistemas de Informações Geográficas (SIG). As áreas consideradas possuem uma extensão igual ou superior a 0,1 ha. A partir dos mapas construídos foi possível realizar uma avaliação temporal da qualidade ambiental urbana associada à vegetação nos bairros.

Ainda, foram realizadas visitas aos bairros para identificação de pontos relevantes sob a perspectiva técnica: vegetação urbana, uso e ocupação do solo e espaços livres. O cruzamento dos dados objetivos e dos dados subjetivos permitiu a avaliação da qualidade ambiental urbana sob um olhar técnico-científico aliado a uma percepção socioambiental da população, trazendo resultados que mais se adequam a realidade dos bairros.

\section{Resultados e Discussões}

\subsection{Vegetação urbana}

A existência de fragmentos florestais em áreas urbanas é um elemento essencial para a adequação ambiental ao conforto ambiental das cidades, uma vez que estão diretamente relacionadas a qualidade de vida da população. As árvores têm função na estabilidade microclimática, em vista de sua capacidade de redução de amplitudes térmicas, aumento das taxas de transpiração, redução da insolação direta, dentre outros (Milano \& Dalcin, 2000). Assim, faz-se necessária a avaliação dos fragmentos vegetais nos bairros estudados, de forma a fundamentar a análise da qualidade ambiental urbana de cada um deles.

Segundo Barros (2015), o bairro Pinherinho contava com nove fragmentos florestais significativos em 2011, totalizando cerca de 31,91 ha de área vegetada, conforme indicado pela Figura 3a. Já em 2018, o bairro contava com oito fragmentos florestais significativos, totalizando cerca de 40,21 ha de área vegetada (Figura 3b). 
Figura 3: Bairro Pinheirinho com fragmentos florestais em 2011 (a) e 2018 (b).
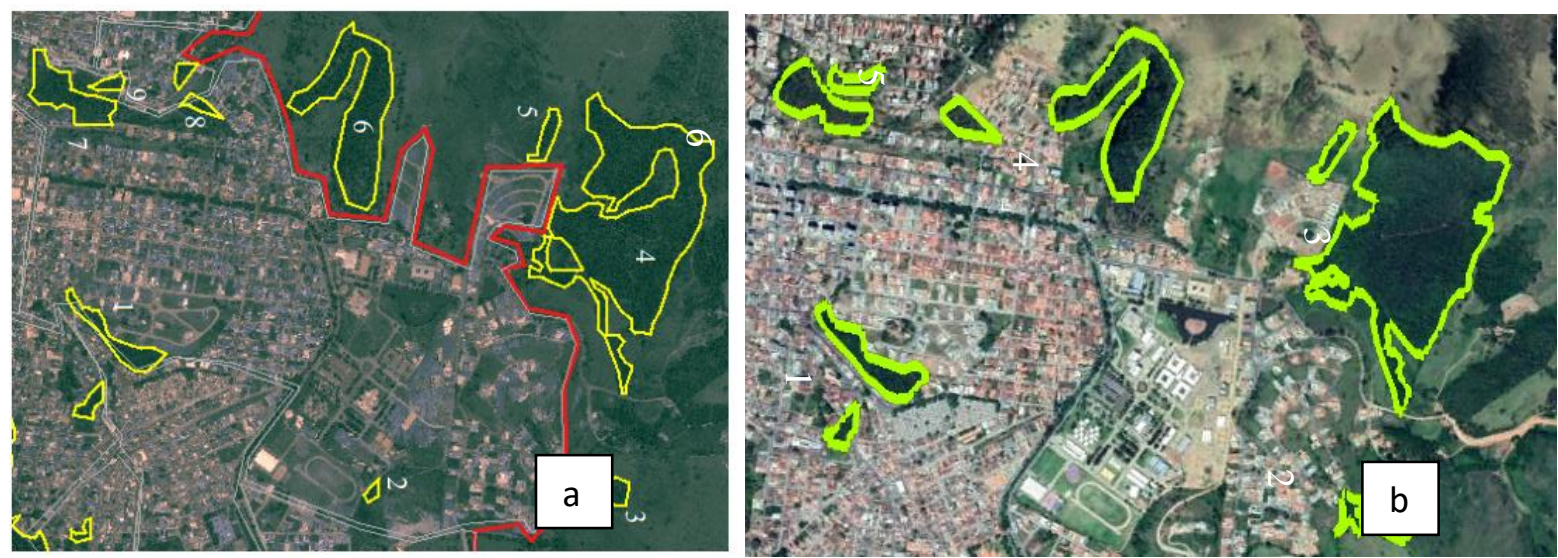

Fonte: a) Barros (2015) e b) Autores.

Nota-se, a partir da análise da Figura 3, que embora a extensão da área vegetada tenha se ampliado, o número de fragmentos significativos foi reduzido com o passar dos anos. Pressupõe-se que a redução da quantidade de fragmentos ocorreu em função da altíssima e atual pressão imobiliária que surgiu com a instalação de condomínios de alto padrão e do complexo de lazer municipal na região.

O crescimento do fragmento 4 (Figura 3a) ocorreu em ordem de sucessão ecológica natural, expandindo sua extensão e cobertura. Vale ressaltar que o bairro Pinheirinho ainda conta com inúmeros espaços passíveis de plantio e de recuperação da vegetação. Dessa forma, cabe ao Poder Público garantir políticas de conservação para que as áreas vegetadas não sejam suprimidas em função da especulação imobiliária e do crescimento horizontal da cidade em direção a essa região de Itajubá.

O bairro Nações, por sua vez, contava com três fragmentos florestais significativos em 2011, totalizando cerca de 3,11 ha de área vegetada (Barros, 2015), conforme a Figura 4a. Em 2018, o bairro manteve seus três fragmentos florestais significativos, totalizando cerca de 3,29 ha de área vegetada, além de indivíduos esparsos distribuídos ao longo do bairro, conforme Figura 4b. 
Figura 4: Bairro Nações com fragmentos florestais em 2011 (a) e 2018 (b).
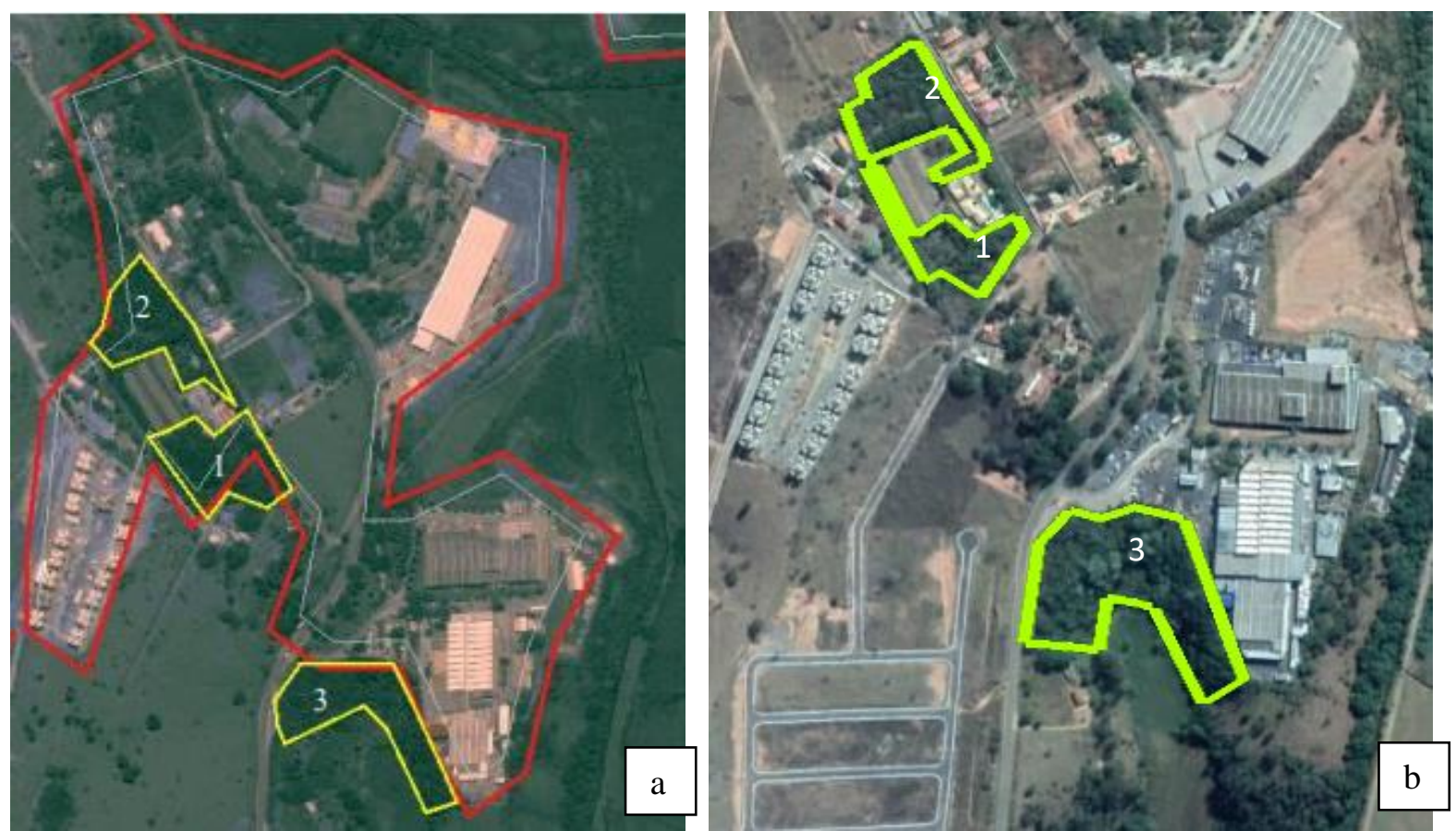

Fonte: a) Barros (2015) e b) Autores.

Não se nota grande expansão da extensão da cobertura vegetal no bairro Nações. É visível, ao comparar as imagens de 2011 e 2018, o surgimento de novos loteamentos na região, que podem vir a se tornar empecilhos a conservação ambiental local. Cabe novamente ao Poder Público regularizar as áreas vegetadas localizadas no bairro e ordenar a expansão urbana, de forma a evitar a supressão vegetal predatória na região.

\subsection{Uso e ocupação do solo}

Conforme o Zoneamento Ecológico Econômico (ZEE) do município de Itajubá, os bairros Pinheirinho e Nações estão localizados em Zona Residencial Unifamiliar (ZRU) e cercados por Zonas de Expansão Urbana (ZEU). Embora classificados em uma mesma definição dentro do ZEE, os bairros possuem características bastante distintas quanto ao padrão de uso e ocupação do solo, como ilustrados pela Figura 5.

Figura 5: Residência (Pinheirinho) (a) e Residencial Vitória (Nações) (b).
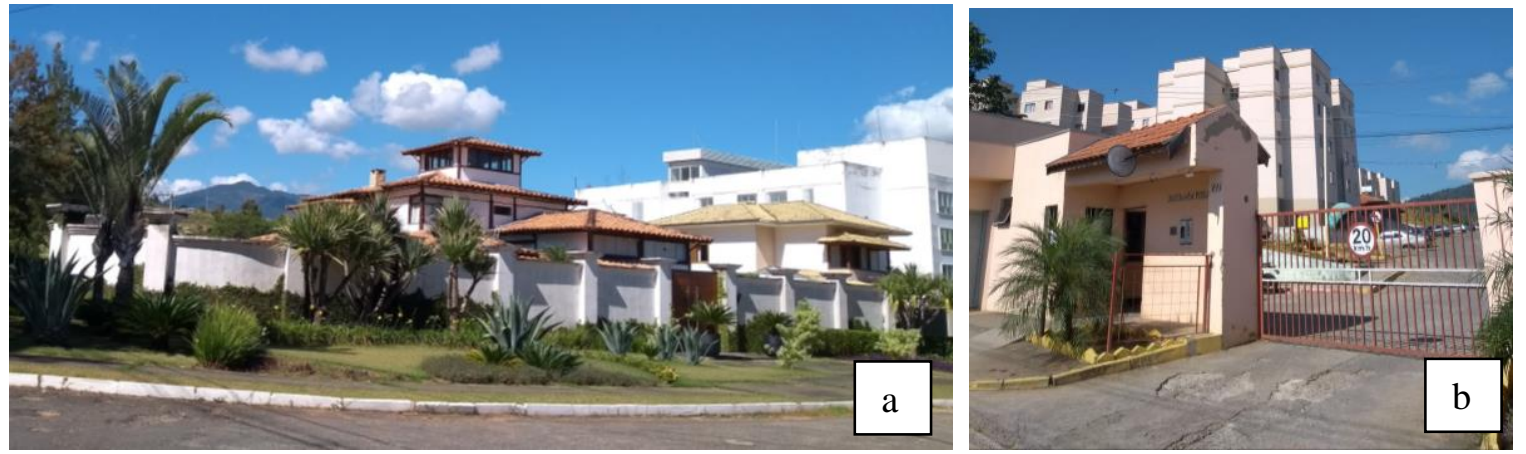

Fonte: Autores.

O bairro Pinheirinho conta com residências de alto padrão (Figura 5a), em loteamentos e condomínios fechados, e 
com a Unifei. É um bairro residencial bastante homogêneo, com poucas instalações comerciais. Nas proximidades do bairro Pinheirinho estão inseridos a prefeitura, escolas e o Parque Municipal de Itajubá.

O bairro Nações conta com chácaras de veraneio, um loteamento e o Residencial Vitória (Figura 5b), composto por apartamentos disponibilizados pelo Programa Minha Casa Minha Vida. No bairro está instalado o Laboratório Nacional de Astrofísica e alguns estabelecimentos comerciais, como uma pequena mercearia, boates e motéis. O bairro não conta com postos de saúde ou escolas, sendo os mais próximos localizados no bairro Jardim das Colinas. Nas proximidades do bairro Nações se encontra o Country Club, entretanto, em conversa com os moradores, foi relatado que não é um local acessível para a população local, uma vez que se destina às classes média/alta.

\subsection{Espaços livres}

Em visita ao bairro Nações, não foram observados espaços livres e áreas verdes (praças, parques, jardins públicos, etc) dentro de seus limites, com exceção de uma academia ao ar livre instalada no interior do Residencial Vitória. Entretanto, terrenos e áreas de solo exposto possuem potencial de instalação de áreas verdes, necessitando uma verificação mais aprofundada dos proprietários e possíveis destinos para tais áreas.

Conforme detalhado pela Figura 6, no bairro Pinheirinho existe a Praça Doutor João Luiz (Figura 6a), localizada em um dos pontos mais altos do bairro, e um lago fechado na região mais baixa (Figura 6b).

Figura 6: Praça Doutor João Luiz (a) e Lago no bairro Pinheirinho (b), Itajubá/MG.
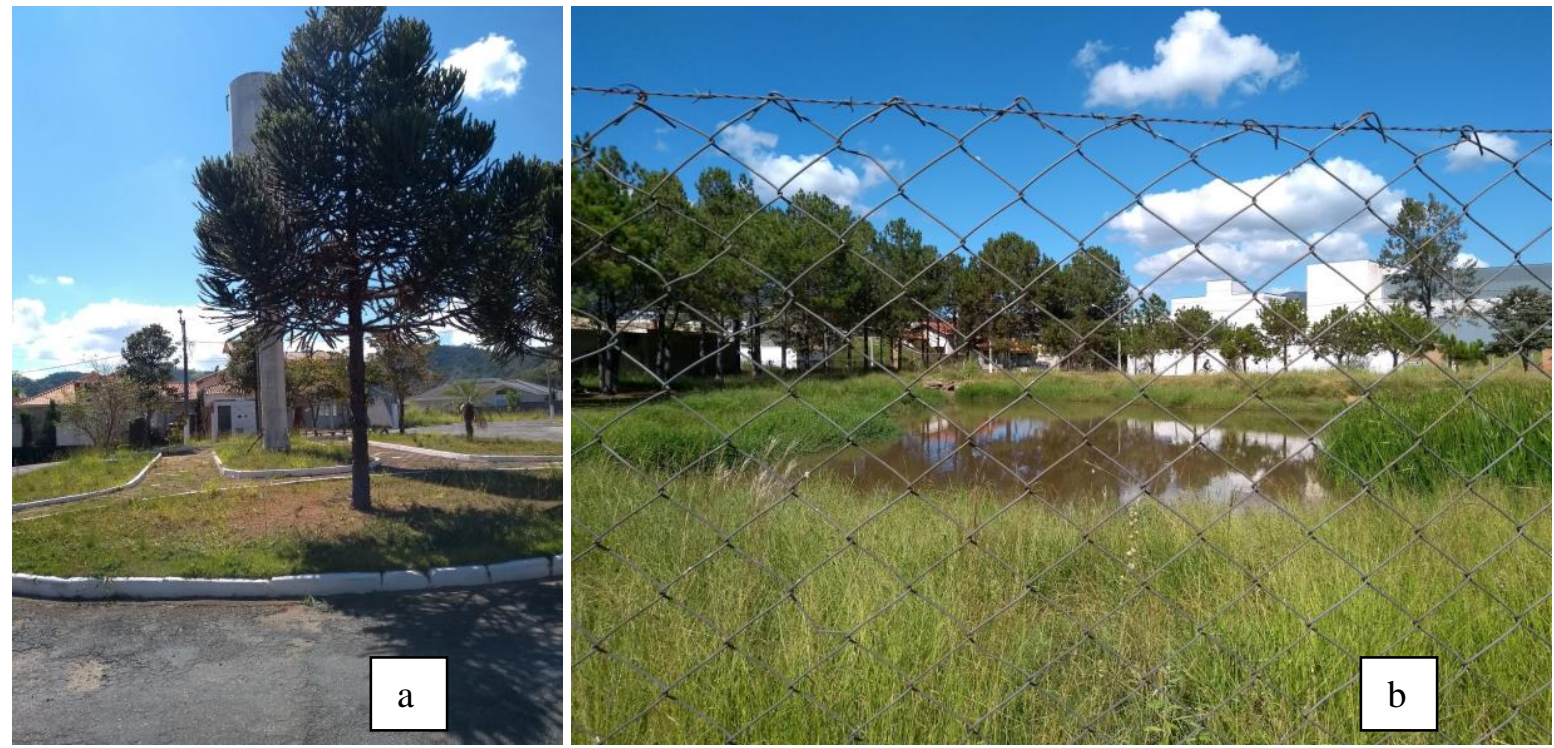

Fonte: Autores.

A praça (Figura 6a) contém bancos em situação precária e uma caixa d'água da Companhia de Saneamento de Minas Gerais - Copasa. O local possui grande potencial para lazer ou descanso, porém precisa de reparos e manutenção, uma vez que atualmente encontra-se em situação bastante degradada. O espaço do lago (Figura 6b), por sua vez, é predominantemente utilizado pelos trabalhadores da construção civil para descanso, graças ao sombreamento proporcionado pelas árvores ao seu redor. Nessa região há grande potencial de desenvolvimento de atividades e instalações de lazer, porém exige reparação e manutenção por parte dos órgãos públicos. Há de se considerar, ainda, a presença de espaços com solo exposto nas fronteiras do bairro, que estão sujeitos a expansão e loteamento por empreendimentos imobiliários. 


\subsection{Percepção do usuário}

Os dados obtidos via questionários permitiram a realização de uma caracterização qualitativa do meio socioeconômica de cada um dos bairros (grau de escolaridade, renda familiar mensal, ocupação profissional, assistência governamental e motivo para residir no local), bem como a avaliação ambiental segundo a percepção dos respondentes, associando o nível de satisfação em residir no local aos principais impactos vivenciados. Após tratamento das informações, os resultados estão apresentados em formatos gráficos para facilitar sua visualização e interpretação.

\subsubsection{Caracterização socioeconômica}

O grau de escolaridade corresponde ao nível educacional que determinado indivíduo possui, indicando as etapas de estudo que foram iniciadas ou concluídas. A Figura 7 representa os dados obtidos para o grau de escolaridade de cada um dos bairros. A coluna "Nulo" diz respeito aos entrevistados que se recusaram a responder à questão.

Figura 7: Grau de escolaridade do bairro Pinheirinho (a) e do bairro Nações (b).

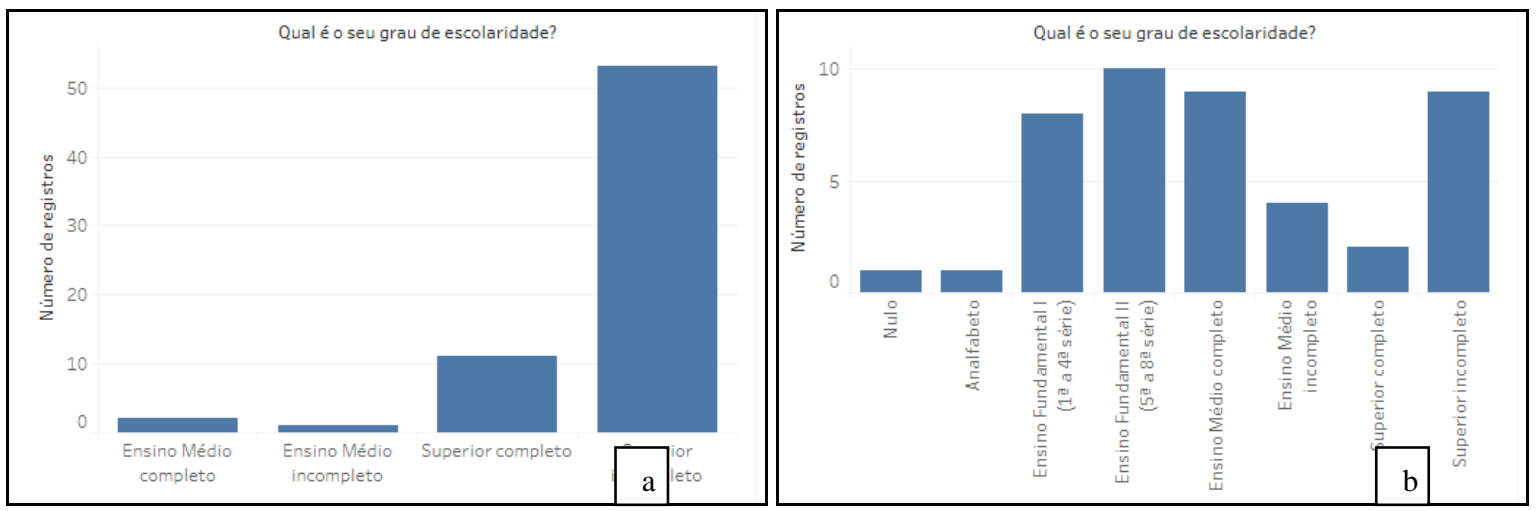

Fonte: Autores.

Nota-se, para o bairro Pinheirinho (Figura 7a), que a grande maioria dos indivíduos entrevistados classifica seu grau de instrução como "Ensino superior incompleto". Tal fato se justifica por se tratar de uma região amplamente ocupada por estudantes da Universidade Federal de Itajubá e por sua disposição em responder os questionários. É evidente, também, a maior acessibilidade dos moradores do bairro Pinheirinho a educação, ressaltado pelos baixos índices de respondentes com grau de instrução inferior ao Ensino Médio completo. O bairro das Nações (Figura 7b), por sua vez, mostra-se bastante variável com relação a educação, incluindo desde moradores analfabetos a moradores com ensino superior completo. Entretanto, apenas $25 \%$ das respostas foi dada por moradores com acesso ao ensino superior, trazendo destaque para o fato de que muitos ainda carecem de oportunidades na educação, uma vez que se estagnaram no ensino médio ou, até mesmo, no ensino fundamental.

A renda familiar mensal é a soma das rendas individuais dos moradores de um mesmo domicílio. A Figura 8 representa os dados obtidos para a renda familiar mensal de cada um dos bairros. 
Figura 8: Renda familiar mensal no bairro Pinheirinho (a) e no bairro Nações (b).

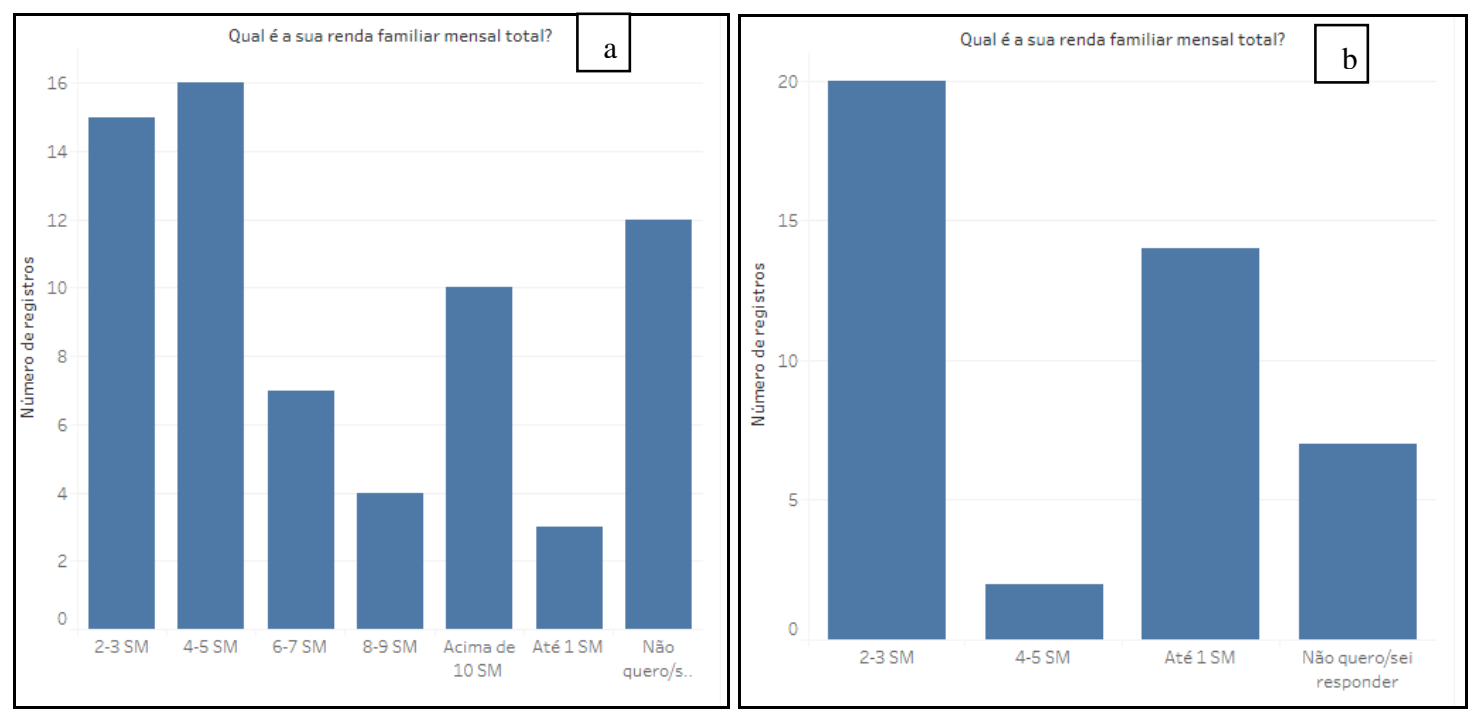

Fonte: Autores.

As famílias que participaram da pesquisa no bairro Pinheirinho recebem em torno de 2 a 5 salários-mínimos mensais, com ocorrências de rendas superiores a 10 salários-mínimos (Figura 8a), revelando uma classe média-alta residente no local. No bairro Nações, a renda familiar mensal está em torno de 1 a 3 salários-mínimos (Figura 8b), caracterizando classes sociais D ou E, segundo a divisão de classes sociais por faixas salário-mínimo do Instituto Brasileiro de Geografia e Estatística (IBGE) (2000).

A ocupação profissional associa-se à atividade com a qual se trabalha. A Figura 9 representa os dados obtidos para a ocupação profissional dos entrevistados de cada um dos bairros. A coluna "Nulo" diz respeito aos entrevistados que se recusaram a responder à questão.

Figura 9: Ocupação profissional dos moradores do bairro Pinheirinho (a) e Nações (b).
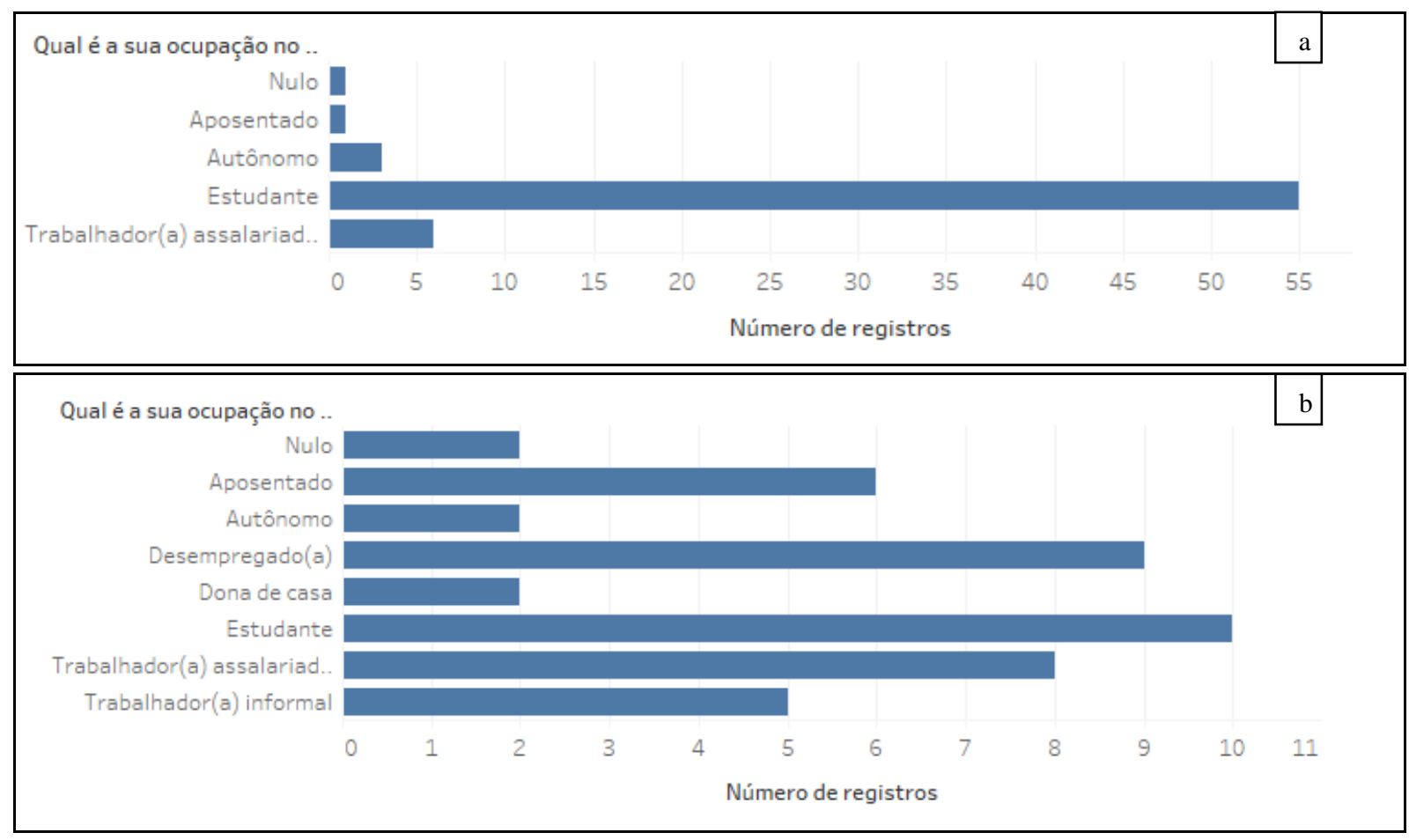


\section{Fonte: Autores.}

O grande número de estudantes no bairro Pinheirinho (Figura 9a) se justifica, novamente, pelo fato de se tratar de uma área amplamente ocupada por alunos da Unifei e sua prontidão em responder aos questionários. O bairro Nações, por sua vez, mostrou números significativos para estudantes, trabalhadores assalariados registrados em carteira de trabalho e desempregados (Figura 9b). Recebe destaque o número de desempregados no bairro Nações, que muito se distancia da realidade observada entre os entrevistados do bairro Pinheirinho, onde o número de respostas referente a ocupação "desempregado" foi nulo.

Foi levantada, ainda, a existência de auxílio governamental a cidadãos de baixa renda. 93\% dos entrevistados que afirmaram receber auxílio governamental residem no bairro Nações, evidenciando uma necessidade assistencialista mais efetiva neste local.

Por fim, a Figura 10 representa os principais motivos levantados pelos entrevistados para residir em cada um dos bairros estudados.

Figura 10: Principais motivos para residir no bairro Nações (a) e Pinheirinho (b).
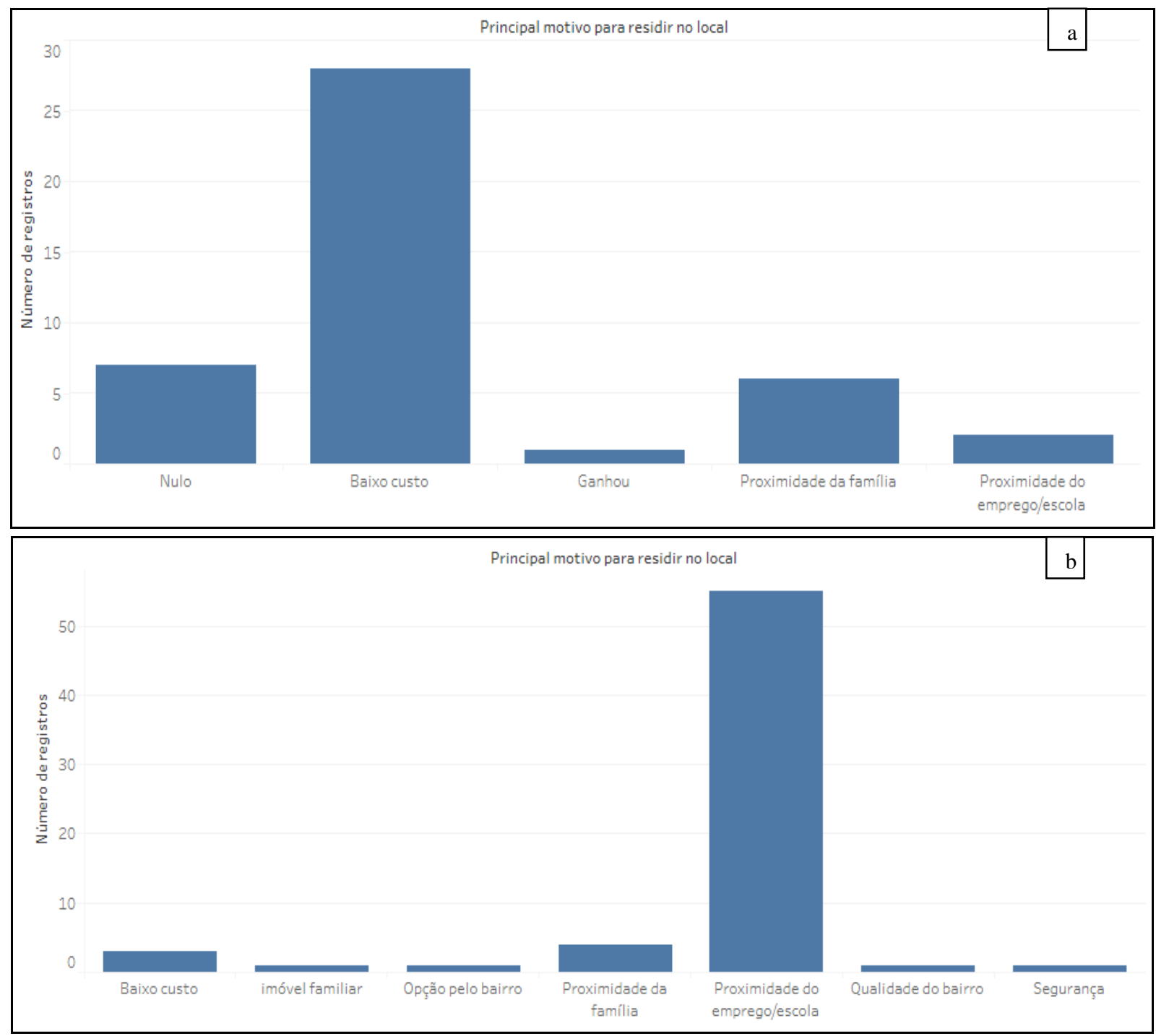

Fonte: Autores.

O que se mostra mais atrativo para os entrevistados, ao se residir no bairro Pinheirinho, é a proximidade da 
escola/trabalho (Figura 10b), enquanto no bairro Nações é notável o interesse pelo baixo custo e pela proximidade da família (Figura 10a). Isso evidencia maior acesso ao emprego e à educação existente entre os respondentes do bairro Pinheirinho. O baixo nível socioeconômico levantado anteriormente para o bairro Nações revela a importância do custo na definição do local para morar.

Em resumo, as condições socioeconômicas dos respondentes do bairro Pinheirinho mostraram-se mais favoráveis do que as apresentadas pelos respondentes do bairro Nações.

\subsubsection{Caracterização ambiental segundo a percepção dos entrevistados}

Para avaliar as condições ambientais, foram levantados os principais impactos socioambientais segundo a percepção dos entrevistados de cada bairro. Dessa forma, os principais impactos socioambientais identificados para os bairros estão apresentados na Figura 11.

Figura 11: Impactos socioambientais observados no bairro Pinheirinho (a) e no bairro Nações (b).

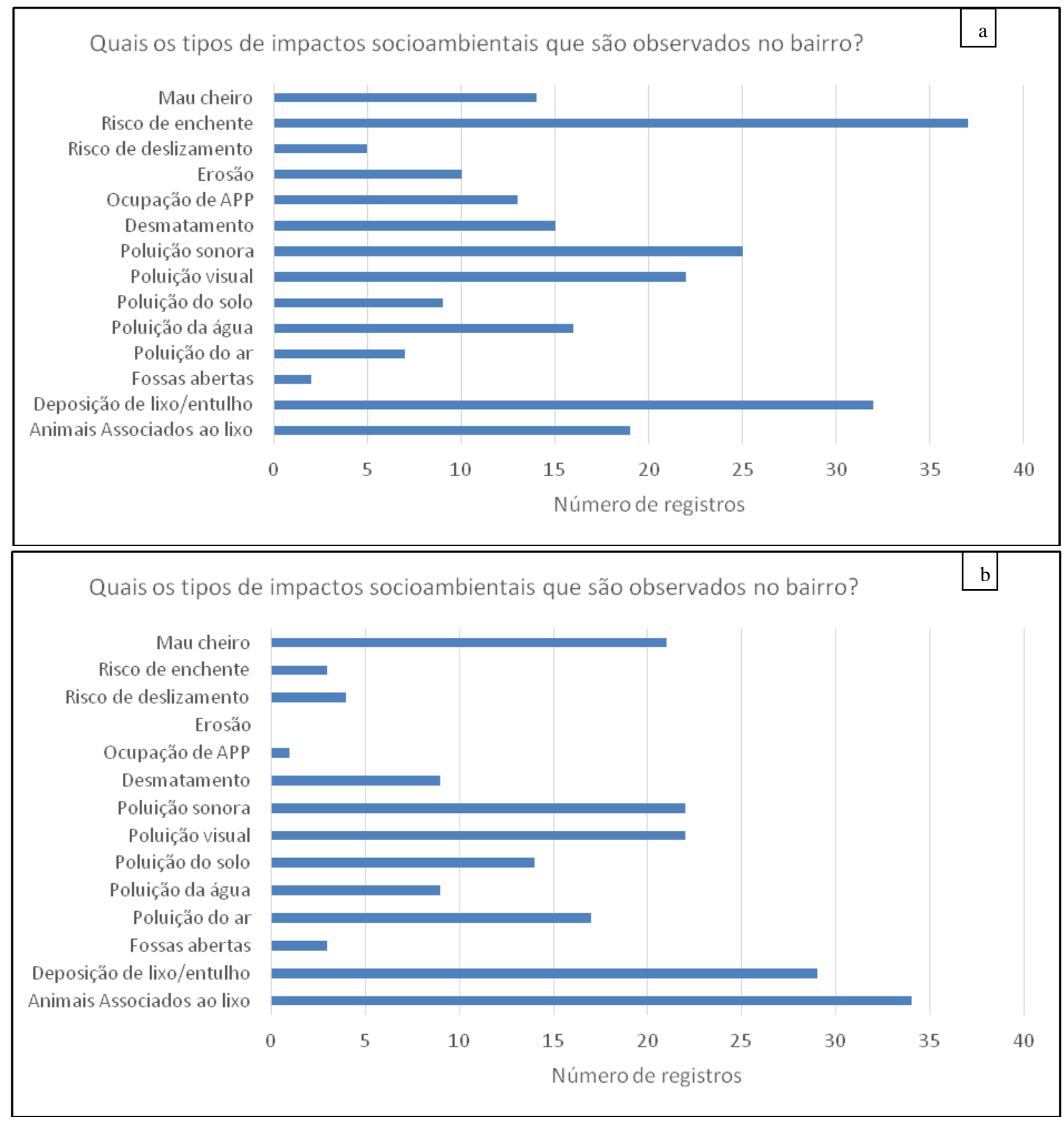


Fonte: Autores.

O bairro Pinheirinho está localizado às margens do Ribeirão José Pereira, região que está sujeita a alagamento em épocas de chuva, corroborando com os resultados obtidos pelos questionários. Além disso, nota-se destaque para a questão de deposição de lixo e entulho em locais inadequados, especialmente nos terrenos vazios do bairro (Figura 11a). Para o bairro Nações, os principais problemas estão relacionados ao mau cheiro proveniente de queimadas constantes e das atividades de um matadouro/frigorífico localizado nas redondezas e aos animais associados ao lixo (ratos, baratas, entre outros) (Figura 11b). Os entrevistados não souberam justificar a existência desses animais, porém foi mostrado grande descontentamento com relação a esse aspecto.

A partir dos gráficos, observa-se que, apesar de englobados pelo mesmo conceito de periferia, os bairros enfrentam problemas distintos associados ao meio ambiente. Assim, a ideia de que a disparidade socioeconômica, associada a características naturais específicas de cada bairro, pode ser um fator determinante na definição da qualidade ambiental de um local assume uma forma mais nítida.

Para avaliar a satisfação dos entrevistados com as condições ambientais de seu bairro, o questionário contou com a questão "Em uma escala de 1 a 4, sendo 1 muito insatisfeito e 4 muito satisfeito, como você classifica as condições ambientais do bairro?". Os resultados obtidos estão apresentados pela Figura 12.

Figura 12: Nível de satisfação dos moradores do bairro Pinheirinho com as condições ambientais do local (a) e nível de satisfação dos moradores do bairro Nações com as condições ambientais do local (b).

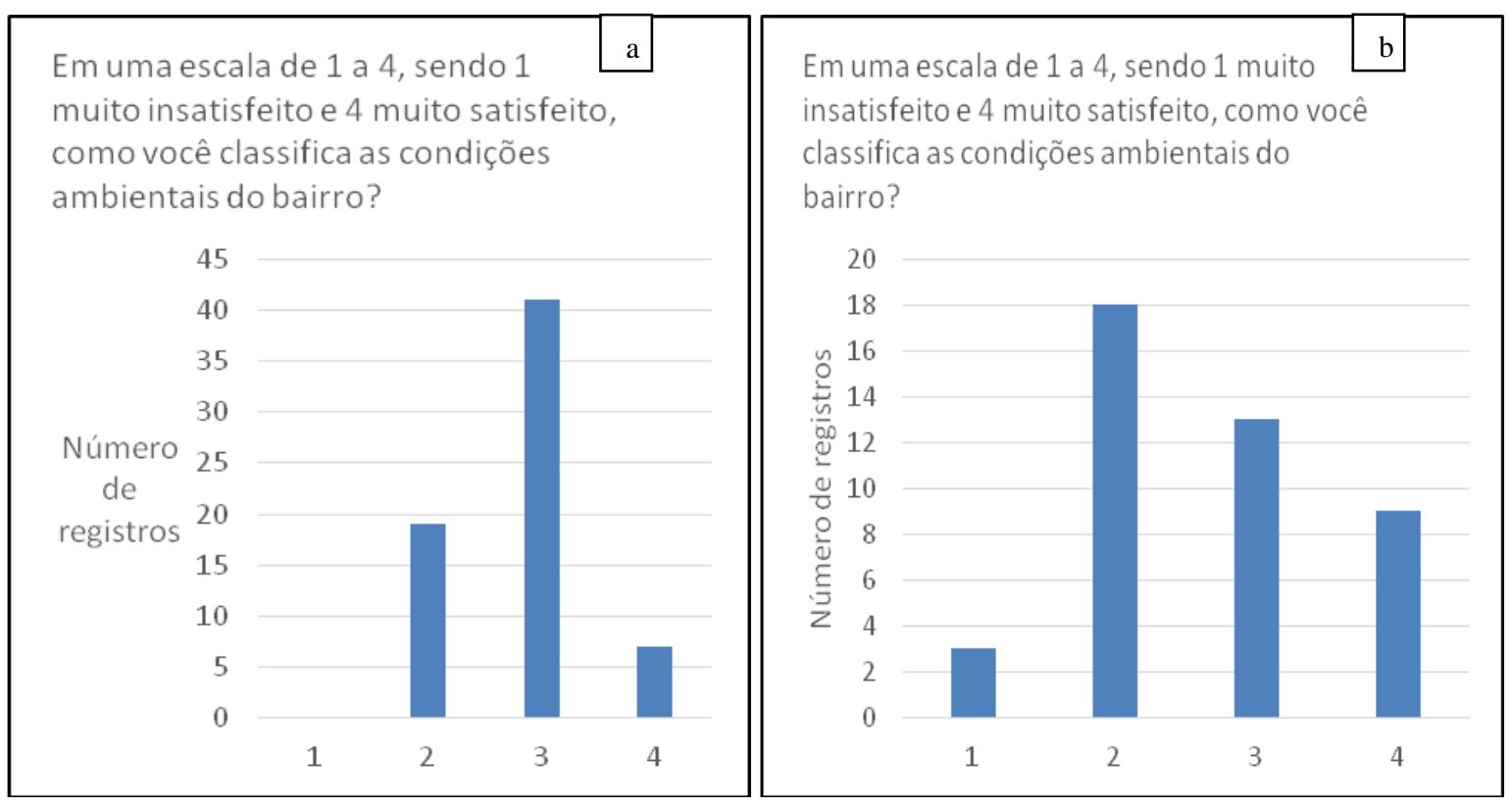

Fonte: Autores.

Apesar da percepção do caos urbano causado pelas enchentes e suas repercussões, os entrevistados do bairro Pinheirinho mostraram-se satisfeitos com o local que residem (Figura 12a). A presença de uma Universidade Federal e a proximidade com centros comerciais sobrepõem-se ao descontentamento com os problemas ambientais, mostrando que a vizinhança, acessibilidade a serviços, disponibilidade de recursos e localização privilegiada são fatores relevantes para a moradia no bairro Pinheirinho. Com base nessas informações, muitos respondentes relataram que não têm vontade de se mudar do local. 
Os entrevistados do bairro Nações, por sua vez, possuem percepções distintas a respeito do local em que estão inseridos e anseiam melhorias ambientais. Apesar de se mostrarem insatisfeitos com as condições ambientais (Figura 12b) e indicarem vontade de se mudar do local, associada a distância de centros comerciais e problemas ambientais, eles possuem sentimentos de pertencimento e paixão pela sua casa e pelo seu bairro. O Programa Minha Casa Minha Vida existente no bairro Nações abriu espaço para que diversos entrevistados realizassem o sonho da casa própria e, por isso, muitos deles relataram que seus apartamentos são conquistas de uma vida melhor, já que suas residências anteriores eram desconfortáveis, ou até mesmo, inabitáveis. Tal fato revela como o espaço físico do Bairro Nações é significativo, em vista dos sentimentos desenvolvidos pelos moradores, e capaz de influenciar os tipos de relações que se estabelecem entre indivíduos e o ambiente (Farias, Gurgel, Diniz, \& Elali, 2017).

\section{Conclusões}

Os bairros Pinheirinho e Nações apresentam problemas socioambientais em suas delimitações e, ainda assim, os entrevistados se mostraram satisfeitos com suas residências.

Algumas dificuldades foram enfrentadas no decorrer da pesquisa, especialmente com relação a coleta de informações. Os moradores do bairro Pinheirinho foram bastante resistentes com relação a aplicação dos questionários. Muitos deles se indispuseram a cooperar com a pesquisa com certo receio dos resultados comprometerem as condições do bairro. No bairro das Nações a recepção dos moradores foi totalmente oposta. A maioria dos entrevistados foi bastante simpática, convidando os pesquisadores para conhecerem suas casas e respondendo as questões com muita disposição.

Com relação ao bairro Pinheirinho, embora localizado em área sujeita a alagamentos e enchentes, ele é considerado, sob a perspectiva dos respondentes, um local vantajoso para se residir. A maioria dos entrevistados possuía condições socioeconômicas favoráveis e relataram que a presença da Unifei, da prefeitura, do Parque Municipal e do teatro municipal são fatores importantes na valorização do terreno.

O bairro Nações também se mostrou alvo de expansão urbana. Embora sua infraestrutura se mostre mais precária que a do bairro Pinheirinho e os moradores mais susceptíveis à fragilidade socioeconômica, não se pode negar a existência de relatos de que o local é vantajoso para se residir. O que foi percebido é um sentimento de apego por parte dos respondentes pelo local em que estão inseridos, resultante da realização do sonho de uma casa própria.

Por fim, nota-se que ambos os bairros enfrentam problemas associados a questões socioambientais. Entretanto, a ligação que os moradores têm com o local onde residem é distinta. Logo, como sugestão para trabalhos futuros, relaciona-se a necessidade de se compreender e descrever como pessoas vivendo em uma mesma cidade possuem percepções distintas a respeito do ambiente em que estão inseridas. Conhecer essa diversidade de percepções pode fundamentar programas de desenvolvimento municipal, de preservação e de conservação ambiental adequados a realidade de cada local e às vivências de cada população.

\section{Referências}

Alier, J. M. (1998). Da Economia Ecológica ao Ecologismo Popular (Português). Blumenau: Editora da FURB.

Barros, D. de P. (2015). Diagnóstico da cobertura vegetal da cidade de Itajubá/MG, utilizando geoprocessamento e proposta de Plano de Manejo (Dissertação de mestrado). Universidade Federal de Itajubá, Itajubá, Minas Gerais, Brasil.

Bonduki, N. G., Andrade, C. R. M. de, Bonduki, N. G., \& Rossetto, R. (1993). Arquitetura \& habitação social em São Paulo, 1989-1992. São Paulo: USPEESC/SAP.

Borja, P. C. (1997). Avaliação da Qualidade Ambiental Urbana: Uma contribuição metodológica (Dissertação de mestrado). Universidade Federal da Bahia, Salvador, Bahia, Brasil.

Brito, F., Horta, C. J. G., \& Amaral, E. (2001). A urbanização recente no Brasil e as aglomerações metropolitanas. Open Science Framework Prepints. 
https://doi.org/10.31219/osf.io/84b92

Caccia, L. S., Evers, H., Fernandes, C. S., \& Betti, L. P. (2017). Sustentabilidade em Habitação de Interesse Social: Benefícios e custos de medidas para eficiência no consumo de água e energia. WRI Brasil.

Camargo, C. E. S., \& Amorim, M. C. de C. T. (2005). Qualidade ambiental e adensamento urbano na cidade de Presidente Prudente/SP. Scripta Nova. Revista Electrónica de Geografía y Ciencias Sociales, 9. Recuperado de https://revistes.ub.edu/index.php/ScriptaNova/article/view/962/.

Chaveiro, E. F. (2007). A periferia urbana em questão: um estudo socioespacial de sua formação. Boletim Goiano de Geografia, 27(2), 181-197. https://doi.org/10.5216/bgg.v27i2.2663.

Evaristo, G. V., Cordeiro, J., Quintão, O. L., Calazans, G. M., \& Cordeiro, J. L. (2016). Saneamento básico e percepção ambiental: um estudo realizado na comunidade Candidópolis em Itabira, Minas Gerais. Research, Society and Development, 4(1), 54-61. https://doi.org/10.17648/rsd-v4i1.28.

Farias, T. M., Gurgel, F. F., Diniz, R., \& Elali, G. A. (2017). A Copa do Mundo 2014 em Natal (RN-Brasil): Um estudo sobre a percepção dos moradores. Research, Society and Development, 5(1), 49-76. https://doi.org/10.17648/rsd-v5i1.90.

Instituto Brasileiro de Geografia e Estatística. (2000). Pesquisa Nacional por Amostra de Domicílios. Rio de Janeiro. Recuperado de https://biblioteca.ibge.gov.br/visualizacao/livros/liv6708.pdf.

Kran, F., \& Ferreira, F. P. M. (2006). Life quality in Palmas - To: An analysis through housing and urban environmental indicators. Ambiente e Sociedade, 9(2), 123-141. https://doi.org/10.1590/s1414-753x2006000200007.

Lima, V. (2014). Análise da Qualidade Ambiental Urbana: O Exemplo de Osvaldo Cruz/SP. Geografia Em Questão, 7(2), 29-46. http://erevista.unioeste.br/index.php/geoemquestao/article/view/9385.

Lobato, C. R. (2004). O espaço urbano (4 ${ }^{\mathrm{a}}$ ed.). São Paulo: Editora Ática.

Maia, D. S. (2010). A periferização e a fragmentação da cidade: loteamentos fechados, conjuntos habitacionais populares e loteamentos irregulares na cidade de Campina Grande-PB, Brasil. Scripta Nova. Revista Electrónica de Geografía y Ciencias Sociales, 14(0). https://revistes.ub.edu/index.php/ScriptaNova/article/view/1730/1706.

Maricato, E. (1999). Metrópole na periferia do capitalismo. Ilegalidade, desigualdade e violência. Capital \& Class, 23(3), 182-185. https://doi.org/10.1177/030981689906900120.

Martine, G., Camarano, A. A., Neupert, R., \& Beltrão, K. (2016). A urbanização no Brasil: retrospectiva, componentes e perspectivas. Anais do VI Encontro Nacional de Estudos Populacionais. Olinda, Pernambuco, Brasil, 6. http://www.abep.org.br/publicacoes/index.php/anais/article/view/456.

Martins, M. de F., Salles, M. C. T., Macedo, E. T. de, Nunes, E. R., \& Ribeiro, R. O. (2020) Problemas urbanos que interferem na sustentabilidade de cidades: um estudo no Município de Serra Redonda-Paraíba-Brasil. Research, Society and Development, 9(8). https://doi.org/10.33448/rsd-v9i8.6177.

Melazo, G. C. (2019). O Projeto Político Pedagógico e as normas complementares para a rede de ensino na Educação Infantil. Olhares \& Trilhas, 21(3), 379394. https://doi.org/10.14393/ot2019v21.n.3.43126.

Milano, M., \& Dalcin, E. (2000). Arborização de Vias Públicas (1ª ed.). Rio de Janeiro: Light.

Nucci, J. C. (2011). Metodologia para determinação da qualidade ambiental urbana. Revista do Departamento de Geografia, 12, 209-224. https://doi.org/10.7154/rdg.1998.0012.0009.

Paviani, A. (1994). Mudança ou transformação na cidade: Uma abordagem preliminar. Geosul, 9(17), 27-40. Recuperado de https://periodicos.ufsc.br/index.php/geosul/article/view/12884.

Pereira, A. K. C., \& Santos, L. de O. L. dos. (2012). Mapeamento dos tipos de uso e ocupação do solo da região do centro da cidade, Santa Inês - MA. VII Congresso Norte-Nordeste de Pesquisa e Inovação, Tocantins, Brasil, 7. http://propi.ifto.edu.br/ocs/index.php/connepi/vii/paper/viewFile/1118/2114.

Pereira, A. S., Shitsuka, D. M., Parreira, F. J., \& Shitsuka, R. (2018). Metodologia da Pesquisa Científica [e-book]. Ed. UAB/NTE/UFSM. https://repositorio.ufsm.br/bitstream/handle/1/15824/Lic_Computacao_Metodologia-Pesquisa-Cientifica.pdf?sequence=1 .

Ritter, C., \& Firkowski, O. L. C. de F. (2009). Novo conceitual para as periferias urbanas. Resumo do VII Seminário Interno de Pós-Graduação em Geografia, Curitiba, Paraná, Brasil, 7. https://doi.org/10.5380/geografar.v0i0.14334.

Santos, A. P., Polidori, M. C., Peres, O. M., \& Saraiva, M. V. (2017). The place of the poor in the city: Theoretical exploration on peripherization and poverty in the production of Latin-American urban space. Urbe, 9(3), 430-442. https://doi.org/10.1590/2175-3369.009.003.AO04.

Santos, D. (2008). Qualidade Ambiental Urbana - Ocupação periférica e percepção em área de proteção e recuperação de mananciais, Zona Sul de São Paulo. Caminhos de Geografia, 9(27), 17-30. Recuperado de http://www.ig.ufu.br/revista/caminhos.html.

Serpa, Â. (2007). O espaço público na cidade contemporânea. São Paulo: Contexto/EDUFBA.

Silva, K. de O. (2006). A periferização causada pela desigual urbanização brasileira. Revista Urutágua, 11, 2-10.

Silva, L. S. e, \& Travassos, L. (2008). Problemas ambientais urbanos: desafios para a elaboração de políticas públicas integradas. Cadernos Metrópole., 19, 22-47. https://revistas.pucsp.br/index.php/metropole/article/view/8708.

Sopran, G. C., \& Debarba, A. L. (2008). O surgimento e aumento da população das periferias da região Oeste de Santa Catarina: Uma abordagem teórica. Uniedu, 1-19. 
Research, Society and Development, v10, n1, e3710111332, 2021 (CC BY 4.0) | ISSN 2525-3409 | DOI: http://dx.doi.org/10.33448/rsd-v10i1.11332

Tavares Filho, T. E. (2017). Educação Ambiental e Qualidade de Vida na Favela. Dialógica: Revista Eletrônica Da FACED, 2(3), 1-16. https://silo.tips/download/educaao-ambiental-e-qualidade-de-vida-na-favela.

Zorzanello, L. B., \& Müller, A. (2013). As diferentes formas de apropriação do solo urbano no bairro Boqueirão em Guarapuava/PR. Caminhos de Geografia, 14(45), 216-236. http://www.seer.ufu.br/index.php/caminhosdegeografia/.

Yin, R. K. (2005). Estudo de caso: planejamento e métodos (2a ed.). Bookman. 